\title{
Effects of regional climate change on rural fires in Portugal
}

\author{
Mário G. Pereira ${ }^{1,2, *}$, Teresa J. Calado², Carlos C. DaCamara ${ }^{2}$, Tomás Calheiros ${ }^{2}$ \\ ${ }^{1}$ Centro de Investigação e de Tecnologias Agro-Ambientais e Biológicas (CITAB), \\ Universidade de Trás-os-Montes e Alto Douro, Vila Real, Portugal \\ ${ }^{2}$ Instituto Dom Luiz, IDL, Universidade de Lisboa, Lisboa, Portugal
}

\begin{abstract}
Wildfires are a major problem in Portugal. Since 1980 an area equivalent to $3 / 5$ of the forested surface has burned. The aim of the study was to assess the potential impact of regional climate change on wildfires in Portugal using an appropriate Burnt Area Model (BAM). Based on multiple regression analysis, the model was able to estimate the decimal logarithm of the monthly burnt areas in July and August using the Daily Severe Rating as a predictor in the pre-fire season (May and June) and the fire season (July and August). The BAM, which was able to explain $63 \%$ of the total observed variance from the 1980-2011 period, was then fed with simulated data by a Global Climate Model (GCM) for the present climate and for two $30 \mathrm{yr}$ periods (2051-2080 and 2071-2100) of future IPCC emission scenario B1. Comparison analysis between the logarithm of burnt area in July and August under present and future climate conditions shows an increase in the mean values of 7 and $11 \%$ for the first and second 30 yr periods, respectively, and a decrease of $32 \%$ in the SD for the first (2051-2080) period but no distinction between the observed and the simulated values for the last (2071-2100) period. Obtained estimates with the developed approach consistently point towards an increasing risk of fire under future climate conditions, and thus an increasing likelihood of much larger burnt areas.
\end{abstract}

KEY WORDS: Climate change impacts - Climate scenario - Forest fire - Multiple regression · Global Climate Model · Model for Interdisciplinary Research on Climate · MIROC - Fire risk

\section{INTRODUCTION}

Weather, climate, fuel pattern and topography are the 4 most important factors driving fire activity (Flannigan et al. 2005, Cary et al. 2006, Nitschke \& Innes 2008, Kloster et al. 2012). The latter factor is static, but the others are continuously changing due to natural variability, human activities and climate change (Solomon et al. 2007). Most aspects of wildland fire are controlled, directly and indirectly, by weather and climate. Meteorological conditions play an important role in all stages of a fire, from its ignition (lightning) to its extinction (precipitation), as well as during its development (wind). Spatial and temporal variability of temperature and precipitation

*Email: gpereira@utad.pt have a very strong influence on fuel availability and flammability at multiple time and spatial scales, with an impact that may greatly vary by ecosystem and wildfire regime (Stephenson 1998, Westerling et al. 2003). For these reasons, on a global scale, climate is the major driver of wildfire extent-high temperature, moderate cumulative precipitation and extended drought periods are among the causal factors of large fires (Aldersley et al. 2011).

To assess the effects of climate change on wildfire activity, it is necessary to also understand fire-vegetation-weather/climate relationships, which in turn crucially depend on the availability of both long-term records of wildfire events and a reliable climatological database. Long-term, extensive fire datasets have

() The authors 2013. Open Access under Creative Commons by Attribution Licence. Use, distribution and reproduction are unrestricted. Authors and original publication must be credited. 
been compiled for several parts of the globe and their quality examined with respect to data inconsistencies and completeness (Brown et al. 2002, Pereira et al. 2011). On the other hand, the scientific community has currently at its disposal large space-time meteorological databases that have undergone several levels of data treatment procedures (e.g. datasets provided by European Centre for Medium-Range Weather Forecasts [ECMWF], European Climate Assessment \& Dataset [ECAD], Climatic Research Unit [CRU], NASA and National Centers for Environmental Prediction/National Center for Atmospheric Research [NCEP/NCAR]). In addition, General Circulation Models (GCMs) are currently able to simulate many global- and regional-scale features of contemporary and future climate scenarios (Wotton et al. 2003), and, for this reason, their projections are commonly used to estimate future fire regimes. With this regard, it is important to mention Lynch et al. (2007), which provides an extensive review of climate-fire interactions as well as the role of climate and fire models to characterize future fire regimes, and Flannigan et al. (2009a) examines several studies on climate-fire interaction and the use of different climate models with different space-time scales.

The impact of climate change on wildfire regimes has been performed at a global scale (Flannigan et al. 2009a, Liu et al. 2010), but most studies focus on wildfire activity at regional or continental scales, e.g. over North America (Wotton et al. 2003, Gillett et al. 2004, Westerling et al. 2006, 2011, Flannigan et al. 2009b), Australia (Lynch et al. 2007), boreal forests of North America and Eurasia (Flannigan et al. 2005, Wotton et al. 2010), and Mediterranean Europe (Pereira et al. 2002, Pausas 2004, Carvalho et al. 2010). In the above-mentioned studies, climate data are used either directly or indirectly by means of fire weather or drought indices and, in general, GCM scenarios are used to project wildfire risk in future climate.

Future warmer climate is expected to be associated with more severe fire activity, including increases in (1) fire intensity (Westerling et al. 2006), (2) area burned or frequency of fires (Wotton \& Flannigan 1993, Wotton et al. 2003, Gillett et al. 2004, Flannigan et al. 2005, Cary at al. 2006, Westerling et al. 2011), (3) fire season duration (Wotton \& Flannigan 1993, Flannigan et al. 2005, 2009a, Westerling et al. 2006, Nitschke \& Innes 2008, Liu et al. 2010) as well as a delay in the fire peak to later in the season (Le Goff et al. 2009).

The problem of quantifying potential changes in burnt area due to climate change is especially relevant in the case of Portugal, where according to the
Portuguese National Forest Authority (Autoridade Florestal Nacional, AFN), >5 million ha have burnt between 1980 and 2006, 1 million ha of which was burnt between 2003 and 2005 (Calado \& DaCamara 2008). The numbers of large fires, amount of burnt area and fire severity have lately increased in Portugal (Marques et al. 2011, Pereira et al. 2011). Despite the severity of the problem, few studies have focused on the effects of climate change on wildfire risk in Portugal (Pereira et al. 2002, Durão \& Corte-Real 2006, Carvalho et al. 2008, 2010, 2011).

Pereira et al. (2005) pointed out that the interannual variability of burnt area in Portugal is largely determined by 2 different atmospheric factors, namely (1) the amount of precipitation during spring (i.e. in the pre-fire season) and (2) the occurrence of atmospheric circulation patterns that induce extremely hot and dry spells over western Iberia throughout the summer season (i.e. throughout the fire season). This result points to the utility of Burnt Area Models (BAMs) based on meteorological variables and/or on fire risk indices defined over the pre-fire and fire seasons. This constitutes the first objective of this work, and, accordingly, a multiple linear model was developed to replicate the interannual variability of the recorded burnt area in Portugal based on meteorological data and/or fire weather indices. The second objective of this work is to assess the potential impact of regional climate change on wildfires in Portugal by feeding the developed BAM with simulated data from a climate model for present and future climate scenario conditions. Finally, an assessment of the possible impacts of climate change on the wildfire regime in mainland Portugal will be made by comparing the statistical distributions of burnt area for present and future climates.

\section{DATA AND PRE-PROCESSING}

The present study relies on 3 different kinds of data: (1) records of rural fires in Portugal, (2) fields of analysed and simulated meteorological variables, and (3) indices of fire risk.

\subsection{Rural fires}

Monthly cumulated values of burnt area in Portugal covering the $32 \mathrm{yr}$ period 1980-2011 were derived from an official rural fire database provided by AFN after correcting the detected data inconsistencies (Pereira et al. 2011). Relying on in situ infor- 
mation collected by the National Firemen Service, the AFN database consists of $>500000$ records of fire events in Mainland Portugal. Since the AFN database does not include urban fires, we will use the term 'rural fires' hereafter instead of 'wildfires'. Pereira et al. (2011) present a comprehensive description of the characteristics, limitations and potential of this dataset.

\subsection{Meteorological variables}

Analysed meteorological data was obtained from ECMWF, namely from ERA-Interim reanalysis (Berrisford et al. 2011, Dee et al. 2011) for the period 1980-2011. Originally, ERA-Interim ran from 1989, but the 10 yr extension for 1979 to 1988 was produced in 2011. ERA-Interim is a reanalysis project initiated in 2006 to provide a bridge between ECMWF's previous reanalysis, ERA-40 (1957-2002) and the next generation extended reanalysis envisaged at ECMWF. The ERA-Interim is based on cycle 31r2 of the ECMWF Integrated Forecasting System and includes many model improvements, such as the use of 4-dimensional variation analysis, a revised humidity analysis and the use of variational bias correction for satellite data. Selected meteorological variables include $2 \mathrm{~m}$ air temperature, $2 \mathrm{~m}$ dew point temperature, $10 \mathrm{~m}$ zonal and meridional components of wind speed, and $24 \mathrm{~h}$ cumulated precipitation. In this study, air relative humidity was computed based on dew point temperature and air temperature, according to the Magnus formula, and corrected with the altitude. The data set, which is defined on a $0.05^{\circ} \times 0.05^{\circ}$ latitude/longitude grid, was restricted to values at 12 UTC and to the grid points covering mainland Portugal.

Simulated meteorological data were obtained from the Model for Interdisciplinary Research on Climate (MIROC; Hasumi \& Emori 2004), a coupled GCM developed by the Centre for Climate System Research (CCSR) at the University of Tokyo, at the National Institute for Environmental Studies (NIES) and at the Frontier Research Centre for Global Change (FRCGC). MIROC is one of the models whose outputs were used in the 4th Assessment Report of the Intergovernmental Panel on Climate Change (IPCC 2007) and several model comparison studies indicate MIROC as one of the best models (Lucarini et al. 2006, Scherrer 2010). In particular, Errasti et al. (2010) compared IPCC AR4 models performance over the Iberian Peninsula and identified MIROC as one of the 4 best models to simulate the present-day Iberian climate. Similar conclusions were found in other studies (Ahlfeld 2006, Lucarini et al. 2006, Nieto \& Rodríguez-Puebla 2006, Tebaldi et al. 2006, Maxino et al. 2008).

Three grid points were selected from the MIROC 3.2 medium resolution (medres) grid: 2 of them located over Portugal and one over Galicia, Spain. Daily grid values of surface air temperature and relative humidity, $10 \mathrm{~m}$ wind speed and $24 \mathrm{~h}$ cumulated precipitation were extracted for the period 19512000, respecting the 20th century model simulations (20C3M), and for 2051-2100, respecting the emission scenario B1 (Nakicenovic et al. 2000). According to the IPCC Special Report on Emissions Scenarios (SRES), the B1 scenario corresponds to a high level of environmental and social consciousness that is accompanied by rapid changes in economic structures and the introduction of cleaning technologies.

Daily spatial means were then computed over the selected grid points over Portugal, and monthly means (of those daily spatial means) were derived for all observed and simulated meteorological variables. Fig. 1 presents the obtained curves that describe the $30 \mathrm{yr}$ seasonal cycles of temperature and precipitation for current and expected future climate. As expected, the largest differences are found for precipitation, where the GCM tends to underestimate the observed monthly rainfall during most of the year

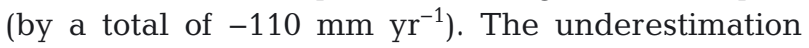
$\left(\sim 25 \mathrm{~mm} \mathrm{mo}^{-1}\right)$ is more significant in spring (April and May) and autumn (September and October) but an overestimation (of $\sim 15 \mathrm{~mm} \mathrm{mo}^{-1}$ ) is also detected in the winter months (December and January). Seasonal cycles of simulated precipitation for B1 scenario conditions in the two $30 \mathrm{yr}$ periods are very similar (mean difference is $<0.7 \mathrm{~mm} \mathrm{mo}^{-1}$ ) with the largest differences being registered during winter and spring ( -8 to $6 \mathrm{~mm}$ ). Differences between simulated precipitation seasonal cycles for future (B1) and recent past $(20 \mathrm{C} 3 \mathrm{M})$ climate scenarios reveal an increasing trend in monthly precipitation between December and March (a total of $30 \mathrm{~mm}$ ) and a decreasing trend in the rest of the year (a total of $-50 \mathrm{~mm}$ ).

With respect to temperature, the GCM tends to underestimate the monthly mean temperature in all months but July $\left(+1.2^{\circ} \mathrm{C}\right)$, the higher differences (between 20C3M scenario and ERA-Interim datasets) being detected in spring and autumn $\left(-1.9^{\circ} \mathrm{C}\right)$. Differences between the 2 periods of future climate scenario B1 suggest an increasing trend in monthly temperature in summer months $\left(1.2^{\circ} \mathrm{C}\right.$ in June and $0.8^{\circ} \mathrm{C}$ in July and August). The seasonal cycle for future climate (B1) presents higher values than for the 

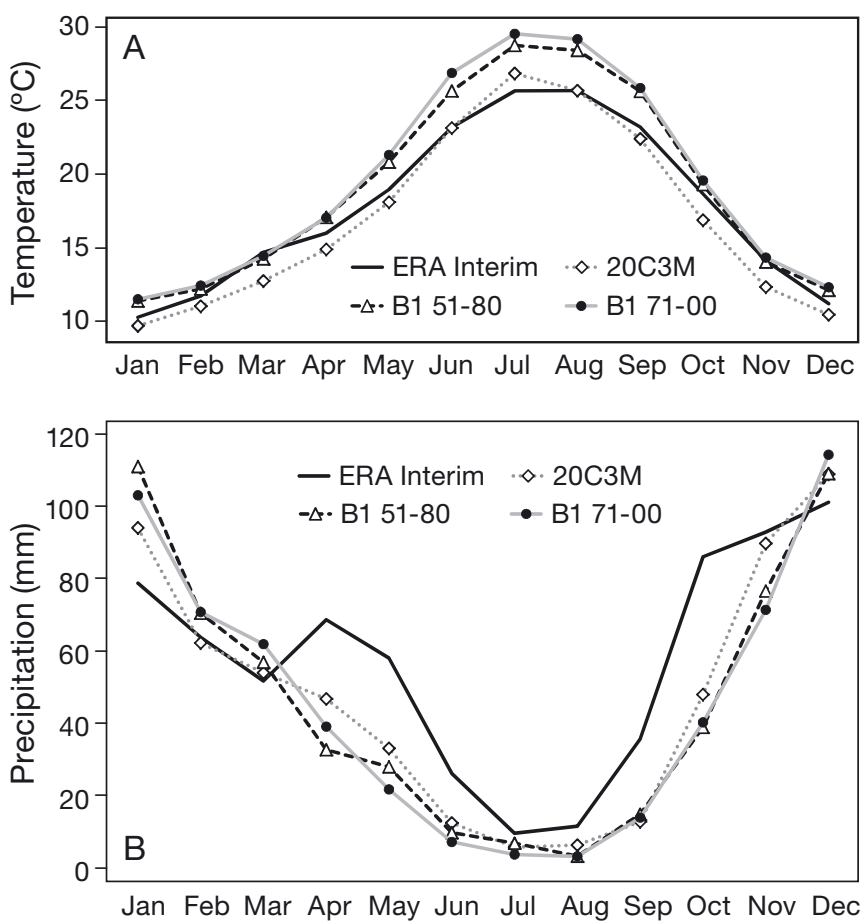

Fig. 1. Monthly mean time series of (A) temperature and (B) precipitation for a $30 \mathrm{yr}$ normal climatological period, using ERA Interim (1981-2010) database and the Model for Interdisciplinary Research on Climate (MIROC) Global Climate Model (GCM) simulations for present 20C3M (1971-2000) and future B1 (2051-2080 and 2071-2100) scenarios

recent past scenario (20C3M), ranging between $1.3^{\circ} \mathrm{C}$ in late winter (February) and $3.4^{\circ} \mathrm{C}$ in late summer (September).

\subsection{Indices of fire risk}

Indices of fire risk are those that integrate the Canadian Forest Fire Danger Rating System (CFFDRS). The system was specifically designed to rate the risk of forest fires in Canada. Like other fire danger rating systems, CCFDRS produces qualitative and/or numerical indices of fire potential, which are used as guides in a wide variety of fire management activities. CFFDRS has been under development since 1968 and currently consists of 2 major subsystems, namely the Canadian Forest Fire Weather Index System (CFFWIS) (van Wagner \& Picket 1985, van Wagner 1987) and the Canadian Forest Fire Behaviour Prediction System (CFFBPS). CFFWIS uses weather information to compute a set of fire indices and has been successfully used all over the world (Wotton 2008). The system consists of 6 components that account for the effects of fuel moisture (first 3 components) and wind (last 3 components) on fire behaviour. The first 3 components, i.e. the Fine Fuel Moisture Code (FFMC), the Duff Moisture Code (DMC) and the Drought Code (DC), respectively rate the average moisture content of surface litter, decomposing litter, and organic (humus) layers of the soil. Wind effects are then added to FFMC leading to the Initial Spread Index (ISI) that rates fire spread. The remaining 2 fuel moisture codes (DMC and DC) are in turn combined to produce the Build Up Index (BUI) that is a rating of the total amount of fuel available for combustion. BUI is finally combined with ISI to produce the Fire Weather Index (FWI) and the Daily Severity Rating (DSR) that respectively rate fire intensity and the difficulty of controlling fires. While FWI is suitable as a general index of fire danger throughout the forested areas, DSR reflects more accurately the expected efforts required for fire suppression (CFS 2011). Moreover, DSR was specifically designed for averaging either in time or in space in opposition to FWI that is suitable as a single day value. The CFFDRS has been operationally used by the Portuguese Weather Service to assess the forest fire risk in Portugal since 1998. The CFFWIS has shown to be especially useful to assess the fire behaviour potential in maritime pine stands in Portugal (Palheiro et al. 2006) and to rate fire risk in Portugal during the summer season (Viegas et al. 1999).

Based on daily values of the above-listed meteorological values (analysed and simulated), DSR values were derived on selected grid points. Following the procedure adopted for the meteorological variables, spatial averages of daily DSR values were evaluated over the selected grid points over Continental Portugal before monthly means of those daily spatial arithmetic averages were finally computed. It may be noted that similar procedures to this one were followed by other authors (e.g. Nitschke \& Innes 2008, Le Goff et al. 2009) who have relied on GCM outputs and on fire weather risk indexes (FWI and DSR) to study future fire regimes under climate change.

\subsection{Observed summer fire regime}

The annual cycle of monthly burnt area for mainland Portugal during the considered $32 \mathrm{yr}$ period (1980-2011) is shown in Fig. 2. The vast majority of fires take place during the summer months and are responsible for a very large amount (88\%) of total burned area. In fact, the fire events in July, August and September account for 24,47 and $17 \%$ of the total burnt area, respectively. These large values are to be expected in Mediterranean regions taking into 
account that vegetation presents elevated levels of water stress, induced by periods of dry conditions and relatively high temperatures that often characterise the late spring and the beginning of summer (Viegas et al. 2001, Pereira et al. 2005, Trigo et al. 2006). The inter-annual variability (as measured by the inter-quartile range) is also clearly larger during the summer months, and it is worth noting that the variability of July and August is about twice the one of September.

Since the burnt areas in July and August account for $71 \%$ of the total burnt area in Portugal, and present very large inter-annual variability, it is to be expected that the annual fire regime will be dominated by the events that take place in those 2 summer months. This is confirmed in Fig. 3 by the close relationship between the time series of annual and of July+August amounts of burnt area. It is also worth noting that both time series present large fluctuations where the outstanding values registered in the years

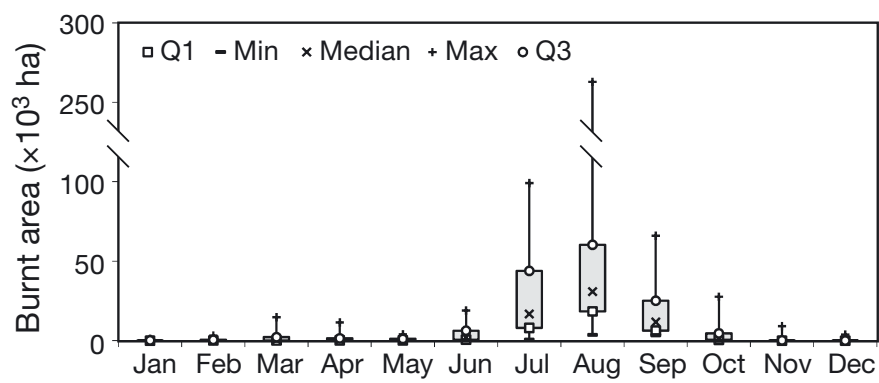

Fig. 2. Annual cycle of monthly burnt area in Portugal for the period 1980-2011. Boxes: monthly values of the lower quartile (Q1), median, and upper quartile (Q3). Whiskers extend down to minimum (min) and up to maximum (max) monthly values

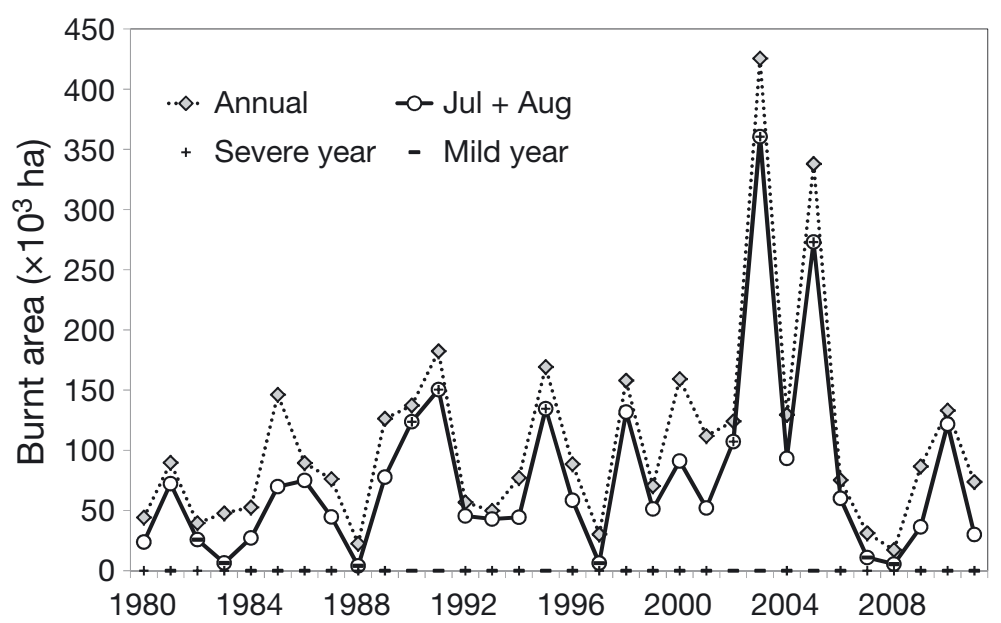

Fig. 3. Inter-annual variability of burnt area amounts in mainland Portugal for the whole year (Annual) and for July + August $(\mathrm{Jul}+\mathrm{Aug})$, for the period 1980-2011. Severe (+) and mild (-) years signs inside respective white circles of 2003 and 2005 contrast with the new all-time low record that was observed in 2007 . The study was therefore restricted to the months of July and August.

With the aim of assessing the association of monthly DSR value to monthly burnt area in July and August, 2 classes of extreme summer fire seasons, respectively labelled severe and mild, were defined according to the following criteria. A severe summer season is one where the monthly burnt areas of July and August are both greater than the upper tercile of the respective month (i.e. $>29000$ ha for July and $>41000$ ha for August); whereas a mild summer season is one where both the monthly burnt areas of July and August are lower than the respective lower terciles (i.e. $<10000$ ha for July and $<22000$ ha for August). As shown in Fig. 3, the years 1990, 1991, 1995, 2002, 2003 and 2005 were severe ones whereas 1982, 1983, 1988, 1997, 2007 and 2008 were mild.

For the 2 defined classes of extreme summer seasons, a composite analysis was performed on monthly anomaly values of DSR and of meteorological variables, from January to August. Composites consist of arithmetic averages over years belonging to a given class, whereas composite anomalies are departures of composites from the grand average of all considered years. Composite analysis was performed to clarify the role and physical interpretation of fire index and meteorological variables in summer burnt area, and, consequently, as a preliminary predictor selection procedure. For each month, the statistical significance of obtained composite anomalies was assessed by estimating percentiles 5, 10,90 and 95 from a sample of 1,000 composites randomly generated using the bootstrapping technique (Efron \& Tibshirani 1993). As shown in Fig. 4, monthly composites of DSR, temperature and precipitation present a contrasting behaviour between severe and mild years that is worth analysing in detail. In the case of DSR associated with severe years (Fig. 4A), 3 consecutive 2 mo periods may be identified: a first period in early spring (March and April) where DSR values are about the grand average (DSR anomalies close to zero), a second period in late spring (May and June) where there is a steep increase in DSR towards very high anomaly values ( $>90$ and 95th percentile), and a third period in summer (July and August) where DSR anomalies stabilize around the very high values that were reached in the preceding period. As shown in Fig. 4B,C, the steep increase in DSR (>95th percentile) is associated with steep increases in temperature (positive anomalies beyond per- 

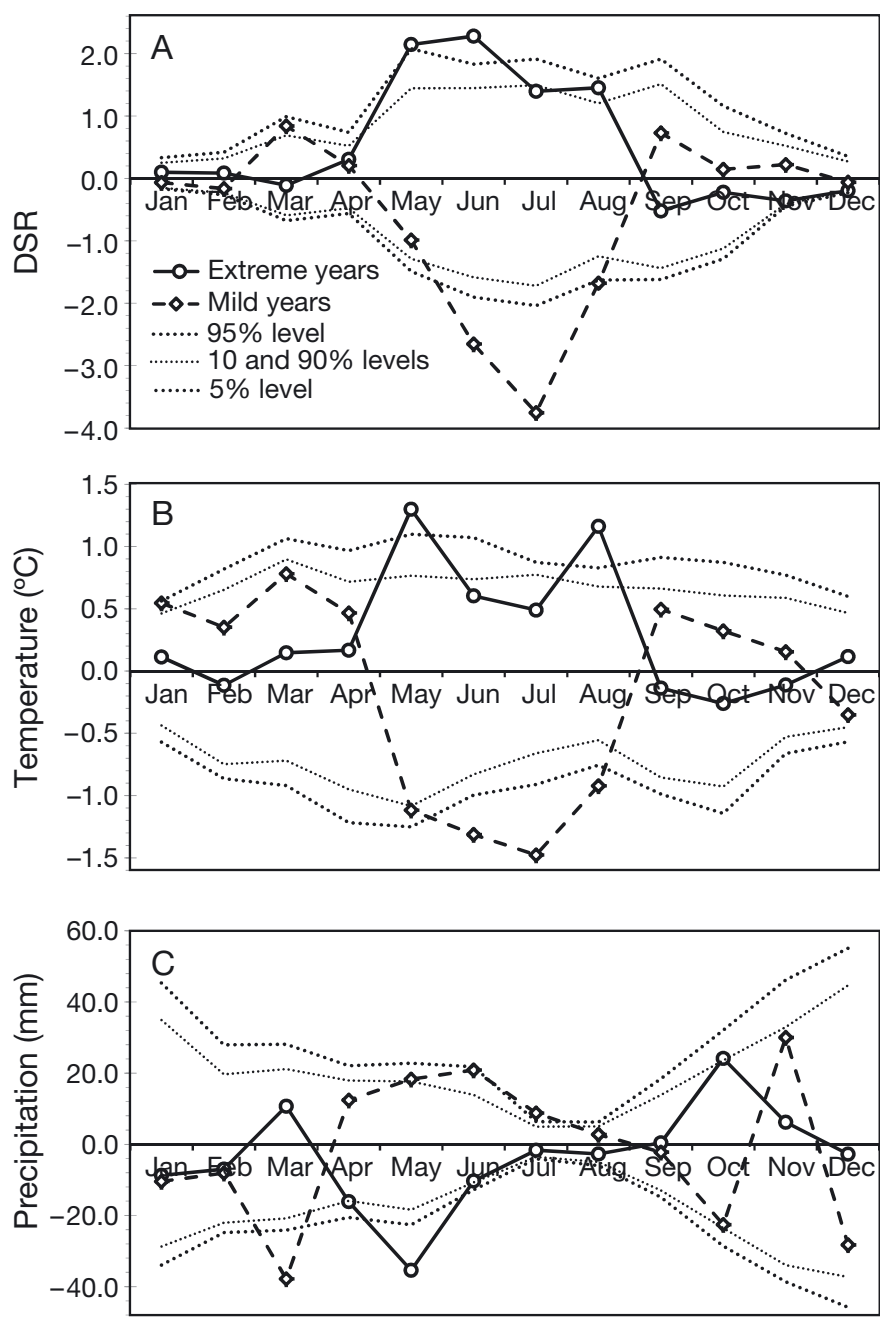

Fig. 4. Monthly anomalies (between January and August) of (A) daily severity rating (DSR), (B) temperature and (C) cumulated precipitation for composites of severe (Extreme years) and mild (Mild years) fire seasons within the 19802011 period. Dotted lines: 95, 90, 10 and 5\% statistical significant level obtained with bootstrapping

centile 95 in May and 90th percentile in June) and to steep decreases in precipitation towards negative anomalies $(<5$ th percentile in May and 10th percentile in June). This particular sequence of weather regimes has a deep impact on the vegetation growing process; the vegetation that has grown in early spring, under favourable average conditions of temperature and rainfall, is then subject to heat and water stress in late spring, making available large amounts of stressed biomass that will trigger large wildfires in case of favourable meteorological conditions, which are very likely to occur in hot and dry summers. This process is in fact very well depicted by the temporal evolution of DSR where the average values in early spring translate into favourable conditions for vegetation growth, whereas the steep increase in late spring and the high values that are reached in summer reflect the increase in stress during late spring and the likelihood of extreme weather events that promote the onset and spreading of large wildfires. The described sequence of weather regimes will therefore favour the occurrence of large fire events in summer that characterize the severe years.

A similar but opposite pattern may be found in the case of the composites associated with mild years. Following a period in early spring (March and April) characterized by large positive anomalies of DSR (particularly in March where the anomaly is >90th percentile), there is a steep decline toward negative anomalies in late spring (particularly in June where the anomaly is lower than percentile 5) followed by a period of very large negative anomalies $(<5$ th percentile) in summer (July and August). Positive anomalies in early spring are associated with positive (negative) anomalies in temperature (precipitation) that will not favour the growth of vegetation, which will be kept unstressed in late spring (May and June) by the very mild and wet conditions associated with the very large negative anomalies of temperature $(<10$ th and 5th percentile, respectively) and the very large positive anomalies ( 90th and 95th percentile, respectively) of precipitation. The large negative anomalies (lower than percentile 5) of temperature in summer, together with the large positive anomalies of precipitation (>95th percentile in July), reflect the absence of extreme weather events favouring the occurrence of large wildfires, in agreement with the very low fire activity that characterizes the mild years.

The existence of a positive $(R=0.67)$ and statistically significant $(\mathrm{p}<0.0001)$ Pearson Product-Moment correlation coefficient between the decimal logarithm of areas burned in July and in August during the period 1980-2011 should be underlined (Fig. 5). However, and despite the statistically significant $(\mathrm{p}<$ 0.0001) high value of the correlation coefficient between DSR and the decimal logarithm of monthly burnt area for the months of July and August ( 0.70 and 0.66 , respectively), there is a very low correlation $(\mathrm{R}=0.25, \mathrm{p}<0.164)$ between DSR monthly means of July and August (Fig. 6). This result, as well as those from the composite analysis, suggest that (1) the burnt areas in July and August are associated with different meteorological fire risk conditions during the summer; (2) the pre-summer season climatological background could also condition the fire regimes 


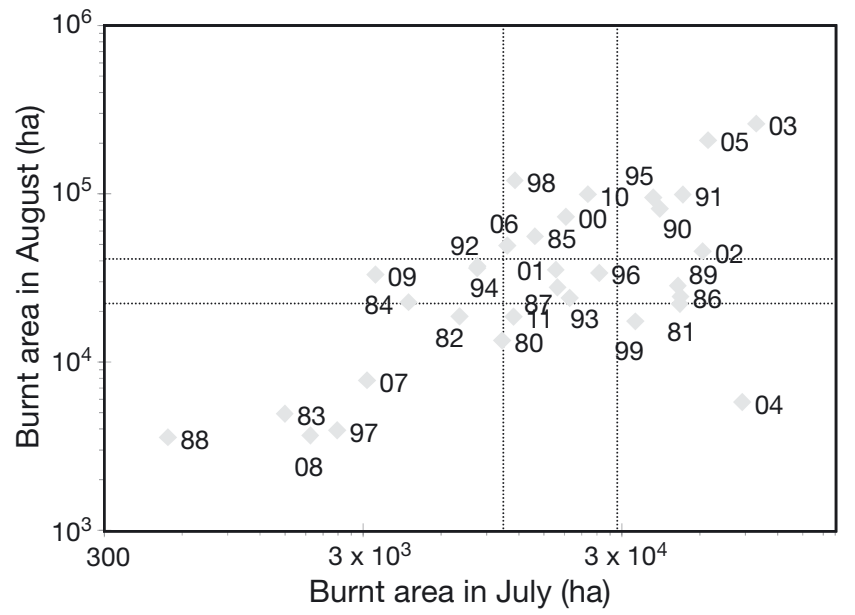

Fig. 5. Log-log scatter plot of July vs. August burnt area values for the period 1980-2011. Individual years: 2-digit labels. Vertical (horizontal) lines: lower and upper terciles of July (August)

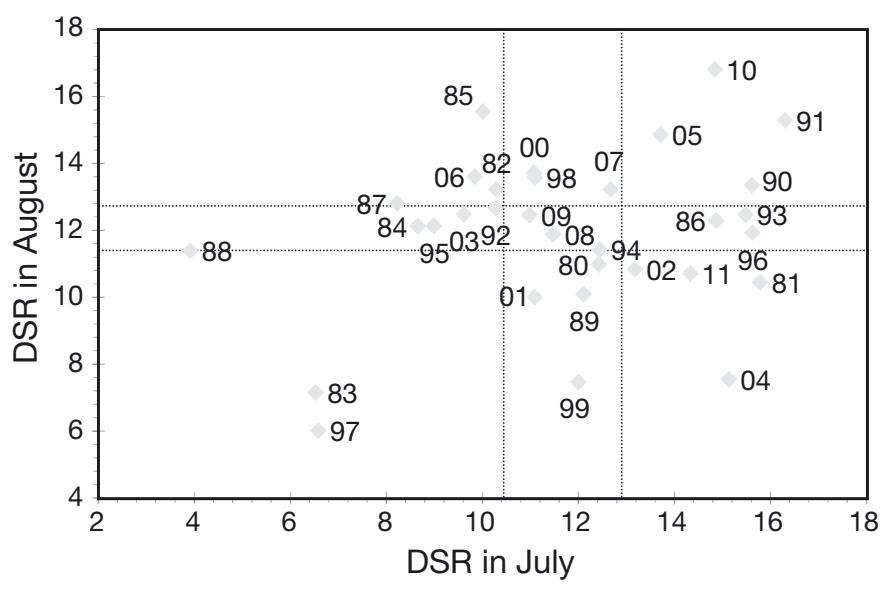

Fig. 6. As in Fig. 5, but for July vs. August daily severity rating (DSR) values

of both July and August; and (3) the development of a BAM by means of multiple linear regression analysis of monthly burnt areas in summer uses, as predictors, fire risk indices respecting the pre-fire and/or fire seasons. Because of the highly asymmetrical character of the monthly means of burnt area in July and August (Fig. 2), the decimal logarithm of monthly burnt area was used as the predictand. As shown in the following section, the transformed variable is normally distributed, which means that the original distribution of the monthly burnt area is lognormal.

Then different automatic selection methods (e.g. stepwise, forward, backward) and criteria (e.g. explained variance, $\mathrm{R}^{2}$ ) were used to select the best predictive variables and test the robustness of the automatic procedures. The best and parsimonious BAM was obtained when using the following equation:

$$
\log _{10} \mathrm{BA}_{\mathrm{J} / \mathrm{A}}=\mathrm{A}+\mathrm{B} \times \mathrm{DSR}_{\mathrm{J} / \mathrm{A}}+\mathrm{C} \times \mathrm{DSR}_{\mathrm{PF}}
$$

where $\log _{10} B A_{J / A}$ is the decimal logarithm of monthly burnt areas in July or in August (J/A); $\mathrm{DSR}_{\mathrm{PF}}$ is the monthly mean of DSR during the pre-fire period $(\mathrm{PF})$, defined as May and June when the predictand is the decimal logarithm of monthly burnt area in July $\left(\log _{10} B A_{J}\right)$, and May, June and July when the predictant is the decimal logarithm of monthly burnt area in August $\left(\log _{10} \mathrm{BA}_{\mathrm{A}}\right) ; \mathrm{DSR}_{\mathrm{J} / \mathrm{A}}$ is the monthly mean of DSR in July or in August depending if the predictand is the monthly burnt area in July or August, respectively. In order to mitigate the effects of overfitting, the performance of the experiments was evaluated using a cross validation procedure that removes $14 \mathrm{yr}$ pairs (i.e. July and August for each year) instead of the more usual and less demanding leave-one-out-cross validation scheme (Wilks 1995).

\section{RESULTS}

\subsection{Modelled summer fire regimes}

The BAM was developed independently for BA time series in July, August and July + August for the $32 \mathrm{yr}$ period (1980-2011). A summary of the main results of the regression analysis and of the analysis of variance (ANOVA) are shown in Tables $1 \& 2$. Obtained results for July and August (independently) are very similar with respect to regressions statistics $\left(\mathrm{R}^{2}=0.60\right.$, adjusted $\mathrm{R}^{2}, \mathrm{R}_{\mathrm{adj}}{ }^{2}=0.57$, and $\mathrm{SE}$ of 0.36 and 0.32 , respectively), regression coefficients (A, B and C) (Table 1), statistical significance (Student's $t$-test distribution statistic and corresponding 2-tailed probability) and ANOVA (Table 2). Results for BAM for July and August are slightly better $\left(\mathrm{R}^{2}=\right.$ $0.63, \mathrm{R}_{\mathrm{adj}}{ }^{2}=0.62$ ), but regression coefficients are very similar to those obtained independently for July and August.

The 2 variables retained in the BAM for July and August are statistically significant and were selected in the order they appear in the equation, with $\mathrm{r}^{2}$ increasing from 0.44 , when $\mathrm{DSR}_{\mathrm{J} / \mathrm{A}}$ is used alone, to 0.63 when $\mathrm{DSR}_{\mathrm{J} / \mathrm{A}}$ and $\mathrm{DSR}_{\mathrm{PF}}$ are used as predictors. Results of the model are shown in Fig. 7, illustrating the overall agreement between observed and modelled values of the decimal logarithm of burnt area 
Table 1. Burnt Area Model regression analysis for July, August, and July + August (1980-2011) which includes: regression coefficients (A, B and $C$ ) and SE using just those coefficients. $\mathrm{R}_{\text {adj }}^{2}$ adjusted $\mathrm{R}^{2}$

\begin{tabular}{|c|c|c|c|c|}
\hline & Coefficients & SE & $t$ & $\mathrm{p}$ \\
\hline \multicolumn{5}{|c|}{ July } \\
\hline A & 2.4952 & 0.2650 & 9.4163 & $<0.001$ \\
\hline B & 0.0973 & 0.0336 & 2.8921 & 0.0072 \\
\hline $\mathrm{C}$ & 0.1009 & 0.0233 & 4.3326 & 0.0002 \\
\hline \multicolumn{5}{|c|}{$\mathrm{R}^{2}=0.60 ; \mathrm{R}_{\text {adj }}^{2}=0.57 ; \mathrm{SE}=0.36$} \\
\hline \multicolumn{5}{|c|}{ August } \\
\hline $\mathrm{A}$ & 2.4715 & 0.3104 & 7.9632 & $<0.001$ \\
\hline B & 0.1005 & 0.0295 & 3.4003 & 0.0020 \\
\hline $\mathrm{C}$ & 0.1072 & 0.0247 & 4.3353 & 0.0002 \\
\hline \multicolumn{5}{|c|}{$\mathrm{R}^{2}=0.60 ; \mathrm{R}_{\text {adj }}^{2}=0.57 ; \mathrm{SE}=0.32$} \\
\hline \multicolumn{5}{|c|}{ July + August } \\
\hline A & 2.4685 & 0.1937 & 12.7445 & $<0.001$ \\
\hline B & 0.1069 & 0.0189 & 5.6429 & $<0.001$ \\
\hline $\mathrm{C}$ & 0.1014 & 0.0163 & 6.2242 & $<0.001$ \\
\hline \multicolumn{5}{|c|}{$\mathrm{R}^{2}=0.63 ; \mathrm{R}_{\text {adj }}^{2}=0.62 ; \mathrm{SE}=0.34$} \\
\hline
\end{tabular}

Table 2. Analysis of variance (ANOVA) including regression $F$-statistic $\left(F_{\text {Reg }}\right)$ and significance of $F\left(F_{\text {sig }}\right)$

\begin{tabular}{|lrrccc|}
\hline & df & SS & MS & $F_{\text {Reg }}$ & $F_{\text {sig }}$ \\
\hline July & & & & & \\
Regression & 2 & 5.7904 & 2.8952 & 21.9352 & $1.58 \times 10^{-6}$ \\
Residual & 29 & 3.8277 & 0.1320 & & \\
Total & 31 & 9.6181 & & & \\
August & & & & & \\
Regression & 2 & 4.4198 & 2.2099 & 21.7332 & $1.71 \times 10^{-6}$ \\
Residual & 29 & 2.9488 & 0.1017 & & \\
Total & 31 & 7.3686 & & & \\
July + August & & & & & \\
Regression & 2 & 11.7115 & 5.8557 & 52.2081 & $6.11 \times 10^{-14}$ \\
Residual & 61 & 6.8419 & 0.1122 & & \\
Total & 63 & 18.5533 & & & \\
\hline
\end{tabular}

using cross-validation. In particular, given the value of the coefficient of determination $\mathrm{r}^{2}=0.63(\mathrm{p}<$ 0.001) for July and August burnt areas, the BAM is able to explain, in cross-validation mode, 3/5 of the total variance. In addition, the KolmogorovSmirnov (K-S) test confirmed the normality of the logarithm of the values of burnt area observed, modelled and residuals from the use of the BAM. These features are especially important and are exploited in Section 3.2 where the developed multiple regression model was used as a generator of monthly burnt area scenarios in present and future climate conditions.
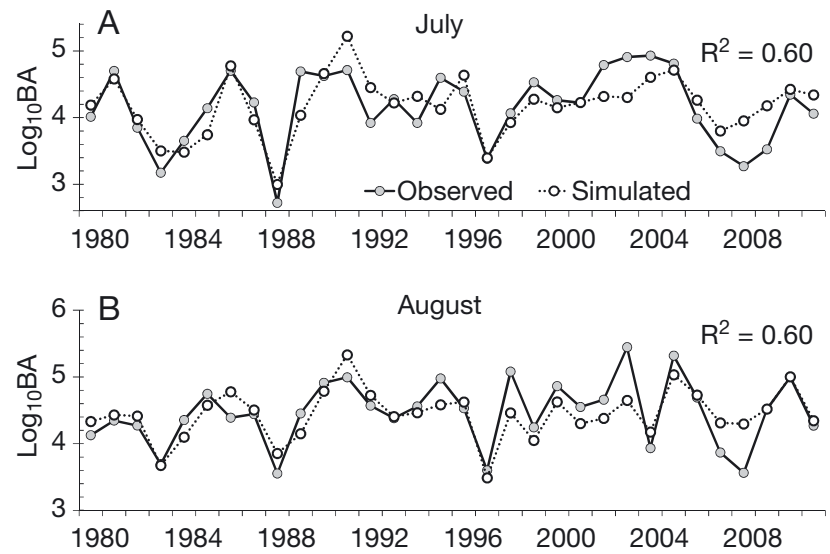

Fig. 7. Observed values (Observed) and modelled values with cross validation (Simulated) of (A) July and (B) August burnt areas (BA) for the 1980-2011 period

\subsection{Simulated summer fire regimes}

Simulated sets of burned areas in July and August were generated by feeding the developed BAM with DSR values for the pre-fire period and for the fire season estimated with GCM outputs with respect to present (20C3M) and future B1 climate scenarios. Based on the results obtained in Section 3.1, normal distributions were fit to observed and simulated monthly values of DSR and to the corresponding burned areas obtained with the BAM. K-S tests were then used to check the null hypothesis that the samples come from normal distribution. The obtained means and SDs of $\log _{10} \mathrm{BA}_{\mathrm{J} / \mathrm{A}}$ are presented in Table 3, together with the p-values of the K-S tests. For all 5 cases of $\log _{10} \mathrm{BA}_{\mathrm{J} / \mathrm{A}}$, the null hypothesis of normality cannot be rejected at the $5 \%$ significance

Table 3. Statistics for one-sample Kolmogorov-Smirnov test for normality for burned areas in July and August, respecting the $30 \mathrm{yr}$ periods of observed values (1981-2010) modelled using Burnt Area Model (BAM) fed with observed meteorological data (1981-2010), and simulated values using BAM fed with Global Climate Model outputs from the present climate scenario 20C3M (1971-2000) and future climate scenario B1 (2051-2080 and 2071-2100)

\begin{tabular}{|lccc|}
\hline & Mean & SD & $p$ \\
\hline Observed (1980-2011) & 4.31 & 0.54 & 0.41 \\
Modelled (1980-2011) & 4.31 & 0.43 & 0.85 \\
20C3M (1971-2000) & 5.06 & 1.06 & 0.42 \\
B1 & & & \\
2051-2080 & 5.63 & 0.72 & 0.38 \\
2071-2100 & 6.03 & 1.07 & 0.68 \\
\hline
\end{tabular}


level. On the other hand, and as expected, the use of the multiple linear model with observed DSR leads to a sample of simulated $\log _{10} \mathrm{BA}_{\mathrm{J} / \mathrm{A}}$ with the same mean as the one of the observed sample but with smaller variance. However, when feeding the BAM with data from climate scenarios produced by a GCM, there is an increase in both the mean and the variance, even in the case of present climate (20C3M). In the latter case, this is an obvious result of the characteristics of the GCM, namely the known fact that the simulated meteorological fields by MIROC, as those of other climate models, are biased and have too much variability. Accordingly, when feeding the BAM with data from a future climate scenario, changes in the mean and in the variance will be due to climate change (signal) as well as to the limitations of BAM and GCM (noise). With the aim of removing the noise, at least in part, the following correction procedure of DSR $\left(\mathrm{DSR}_{\mathrm{PF}}\right.$ and $\mathrm{DSR}_{\mathrm{J} / \mathrm{A}}$ ) was applied:

1. The normal distribution, $N(5.06,1.06)$, that was obtained with the BAM using data from the 20C3M scenario was transformed into a normal distribution, $\mathrm{N}(4.31,0.54)$, with the same mean and variance of the observed data (Table 3); this may be achieved by applying the following transform to the data:

$$
\log \mathrm{BA}_{\text {corr }}=\frac{\log \mathrm{B} A-\mid 5.06-\frac{1.06}{0.54} \times 4.31}{\frac{1.06}{0.54}}
$$

2. The same transform was applied to the normal distributions, $\mathrm{N}(5.63,0.72)$ and $\mathrm{N}(6.03,1.07)$, that resulted from feeding the BAM with 2051-2080 and 2071-2100 data from B1 scenario of future climate (Table 3).

Descriptive statistics of the normal distributions of the decimal logarithm of burnt area $\left(\operatorname{LogB} A_{J / A}\right)$ can be found in Table 4 . When compared with the present climate scenario (20C3M), there are increases in the means of LogBA in both future climate scenario (B1) periods 2051-2080 and 2071-2100 respectively of $7 \%$ (4.31 to 4.60 ) and $11 \%$ (4.31 to 4.80 ). The same does not happen in the case of the standard deviation where a contrast is found for the 2 periods of the future climate scenario; the standard deviation remains unchanged from the 20C3M to the last period of B1 scenarios, but presents a decrease of $\sim 32 \%$ (0.54 to 0.37 ) from the $20 \mathrm{C} 3 \mathrm{M}$ to the first $30 \mathrm{yr}$ of B1 scenario. In addition, differences in percentiles change with increasing percentiles, e.g. from 0.39
$(0.36)$ in $\mathrm{P}_{5}$ to $0.48(0.58)$ in $\mathrm{P}_{50}$ and $-0.28(0.39)$ in $\mathrm{P}_{95}$ when going from present climate to first (last) $30 \mathrm{yr}$ period of B1 scenario. This is an important aspect, since it reveals that for the 2051-2080 period, major increases in burnt area are only expected for values below $\mathrm{P}_{75}$ and the larger increases should be expected for $\mathrm{P}_{10}(0.58)$ values of burnt area, while for the 2071-2100 period, increases are therefore to be expected for all values of burnt area, but larger increases are found between $\mathrm{P}_{10}(0.55)$ and $\mathrm{P}_{75}(0.47)$.

Differences are more impressive when analysing changes in burnt area (and not in the logarithm) from present to future climate scenarios, e.g. by looking at the measures of location and dispersion of the corresponding log-normal distributions (Table 5). The medians from the $20 \mathrm{C} 3 \mathrm{M}$ scenario to the first and last $30 \mathrm{yr}$ periods of the B1 scenario increase from 16000 to 49000 and 61000 ha, respectively. On the other hand, the mean remains unchanged from 20C3M to the 2051-2080 period of B1, but increases to 158000 ha with the 2071-2100 period of future scenario. The weight of extremely large values of burnt area is also well apparent given the growing differences between the median values associated with the large positive skewness of the log-normal distributions.

Table 5. Measures of location and dispersion respecting the lognormal distributions of monthly burnt area for present (20C3M) and future (B1) climate scenarios. IQR: interquartile range

\begin{tabular}{|lcccc|}
\hline & $\begin{array}{c}\text { Mean } \\
\left(10^{3} \text { ha }\right)\end{array}$ & $\begin{array}{c}\text { Median } \\
\left(10^{3} \text { ha }\right)\end{array}$ & $\begin{array}{c}\text { IQR } \\
\left(10^{3} \text { ha }\right)\end{array}$ & $\begin{array}{c}\text { Relative } \\
\text { dispersion }\end{array}$ \\
\hline 20C3M & & & & \\
$1971-2000$ & 51 & 16 & 34 & 1.05 \\
B1 & & & & \\
$2051-2080$ & 52 & 49 & 45 & 0.45 \\
2071-2100 & 158 & 61 & 100 & 0.82 \\
a Defined as the semi-interquartile range divided by the \\
median
\end{tabular}


Increases may also be found in dispersion, taking into account that the inter-quartile range increase from 34000 ha, in the case of the 20C3M scenario, to 49000 and $100000 \mathrm{ha}$, in the case of first and last $30 \mathrm{yr}$ period of B1 scenario. However, relative dispersion presents a rather different behaviour of the mean and the median: that is, a decrease from 20C3M to the 2051-2080 (1.05 to 0.45) and 20712100 (1.05 to 0.82 ) periods of B1.

\section{DISCUSSION AND CONCLUSION}

An analysis was performed of the influence of meteorological factors on the wildfire regime in mainland Portugal, as well as of the future impacts to be expected from regional climate change. It was shown that the annual wildfire regime is dominated by the fire events taking place in July and August, the 2 summer months accounting for almost $3 / 4$ of the total burnt area.

The influence of meteorological conditions on fire occurrences was disclosed by means of composite analysis of relevant variables, which was performed on severe and mild years, defined as those where both the monthly burnt areas of July and August are higher or lower than the respective upper or lower terciles, respectively. Results indicated that severe years are related to averaged anomalies of precipitation in March followed by positive anomalies of temperature and negative anomalies of precipitation and relative humidity in the pre-fire season, while for mild years the results are precisely the opposite. Atmospheric circulation over Portugal is consistent with these climatic patterns. The behaviour of precipitation and temperature anomalies for the 2 classes of extreme years, as well as of humidity and wind (not shown for sake of simplicity) were consistent with the results obtained for the fire risk index, with the anomalies of DSR becoming increasingly positive and statistically significant from May to June for severe years. Differences were also obtained during the fire season (July and August), where extremely meaningful positive (negative) anomalies of temperature and DSR (i.e. >90 or 95\% significant level) were found for severe (mild) year composites.

Differences obtained in meteorological parameters may be understood in terms of the impact of meteorological factors on thermal and water stress of vegetation. In the case of severe years, there is an above average and relative humidity (i.e. positive anomaly) in March that increases the likelihood of a healthy growth of vegetation. The low values of precipitation that follow in May and June, together with the high values of temperature, increase stress in the more abundant vegetation contributing to a larger amount of burnt area, especially if, during the fire season, Portugal is affected by atmospheric circulation patterns that induce extreme hot and dry spells over the territory, which is clearly suggested by wind anomalies. In the case of mild years, the pattern is identical but symmetrically opposite.

Composite and correlation analysis results point to the existence of 2 periods, namely during the fire season and before the time of fire, where the weather plays, directly or indirectly, an important role in the amount of area burned during the months of July and August. This has been pointed out in previous studies that indicate that the summer burnt area in Portugal is related to the existence of a relatively long dry period during late spring and early summer and the occurrence of extreme dry and hot days associated with extreme synoptic situations (Viegas et al. 2001, Pereira et al. 2005, Trigo et al. 2006). A similar relation between burnt area and summer drought has been identified in Greece (Dimitrakopoulos et al. 2011).

A BAM was developed by means of multiple linear regression analysis of the decimal logarithm of monthly burnt areas in the fire season using, as predictors, the DSR during the pre-fire season and the DSR during the fire season. An overall relation was obtained between the observed and modelled values, with the developed model being able to explain $\sim 2 / 3$ of the total observed variance. The results of cross validation reveals that the model is not strongly affected by overfitting, and allows us to be confident in the performance of the model when used in practice with a future unknown validation dataset. This outcome is most likely associated with the relatively large size of the training data in comparison with the small number of parameters in the model. The developed BAM was then fed with simulated data by the MIROC climate model, respecting present climate conditions (20C3M) and future climate IPCC emission scenario B1. It was shown that values of DSR computed with observed and simulated meteorological data followed normal distribution. The same is also true for samples of observed logarithms of July and August burnt areas, as well as those obtained by feeding the BAM with data from 20C3M and B1 scenarios. An increase in both the mean and the variance was however found, even in the case of the present climate, when comparing the simulated normal distributions with the observed one, indicating that changes in the mean and variance in the future 
climate scenario were due to both climate change and limitations of BAM and GCM. An attempt to mitigate the influence of such limitations was made by correcting the normal distribution of DSR for simulated present climate in such a way as to have the same mean and variance as the one observed, and then by applying the same correction to the normal distributions respecting the B1 scenario.

When comparing the present climate scenario (20C3M) with the 2 periods (2051-2080 and 2071$2100)$ of future climate scenarios B1, there were increases in the means of the logarithm of July and August burnt area, respectively, of 7 and $11 \%$, whereas the standard deviation remained almost unchanged in the latter case of scenario B1 and presented a decrease of $\sim 30 \%$ in the case of the former period. Differences in percentiles (between present and future climate scenarios) increased with increasing percentiles, indicating that larger increases in burnt area are to be expected for all fire events at the end of the 21 st century.

Taking into account that monthly burnt area in July and August accounts for $71 \%$ of annual burnt area, only 5 burnt area values are greater than the maximum observed value of $430000 \mathrm{ha}$, registered in 2003 (Fig. 3), and all of these highest values may be found in the decade 2090-2099. Nevertheless, it is very likely that the simulated amounts of burned area are overestimated, relating the following factors: (1) the use of GCMs or regional circulation models (RCMs), (2) the use of a linear BAM, and (3) not taking into account other important factors regarding fire occurrence and size. In general, climate change-fire studies are based on GCM or RCM which, in fact, are just limited representations of reality. To try to circumvent these difficulties, some authors prefer to use data from more than one model or runs from the same model, aiming to obtain a more 'realistic' projection of the 'true' future climate and/or to estimate the error committed in their analysis (e.g. Nitschke \& Innes 2008) or to use RCM with higher spatial resolution (e.g. Pereira et al. 2002, Durão \& Corte-Real 2006, Carvalho et al. 2010). Alternatively, each model performance can be evaluated and, for instance, the inter-comparison of the model-based projections for the new IPCC emissions scenarios points out that the MIROC models have a small decrease $(\sim 10 \%)$ in spring precipitation and a rise of $4^{\circ} \mathrm{C}$ in mean spring temperature during the 2070-2099 period, in Southern Europe and Northern Africa. MIROC models also present the largest temperature change for that period when compared with the other analysed models. In particular, the mean temperature in summer is projected to increase by at least $6^{\circ} \mathrm{C}$ and precipitation is projected to decreases by $40 \%$. In this respect, it is worth stressing that the developed BAM relies indirectly (through DSR) on spring and summer temperature and precipitation.

On the other hand, there are the limitations of the BAM which, by being a linear regression model, it is only able to explain a partial amount of the interannual variability (even if it explains up to $2 / 3$ of the total variance). These limitations are expected to be even more restrictive when the model is applied to future climate scenarios, i.e. to meteorological conditions beyond the range of the tested domain. The linearity of the approach prevents the introduction of feedback mechanisms that might reduce the amounts of burnt area.

It is likely that climate change will have significant relative impact on the beginning and end of the fire season. In fact, the arithmetic averages of DSR in the pre-fire in the first and last $30 \mathrm{yr}$ periods of the B1 scenario are higher than for those for scenario $20 \mathrm{C} 3 \mathrm{M}$ by 35 and $60 \%$, respectively. These results may suggest an increase in the length of time of fire and, therefore, a potential limitation of the approach by restricting the analysis of the burned area to the period of July and August.

Other limitations come from the fact that the methodology does not account for the role of, and potential future changes in, many other important factors regarding fire occurrence and size that are not yet fully understood nor properly modelled, such as those related to changes in fuel structure (Pausas 2004, Pausas \& Bradstock 2007); climate-vegetation dynamics and conservation planning (Krawchuk et al. 2009); patterns of lightning strikes (Dissing \& Verbyla 2003); and anthropogenic activities and drivers of fire, such as control over ignition, fire management, suppression activities, and land use/land cover changes (Krawchuk et al. 2009, Costa et al. 2010, Le Page et al. 2010, Aldersley et al. 2011, Kloster et al. 2012).

In addition, many of the climate change-fire interaction studies are based on 'fire weather' risk assessments that were developed for regions, climates and vegetation characteristics quite different from those where they are being used. However, the validity of using the FWI and DSR indexes in the Mediterranean region has been demonstrated previously in several published works and adopted by the national and European Commission authorities. Nevertheless, they should be adaptated to the climate and vegetation characteristics in this region. 
Obtained estimates of July and August burnt areas in future climate need therefore to be looked at with due care, even if the results are of the same order of magnitude as others recently published. For instance, Carvalho et al. (2010) investigated the impact of future climate change on fire activity in 12 districts across Portugal using historical relationships and simulations of the High Resolution Hamburg Model (HIRHAM). They have estimated an increase of $280 \%$ in the number of fires and of $480 \%$ in burnt area for all 12 districts in the case of a $2 \times \mathrm{CO}_{2}$ scenario. Such an increase could even surpass $600 \%$ in some districts. Nitschke \& Innes (2008) used FWI and 3 GCM scenarios to study the relation between climatic change and fire potential in South-Central British Columbia, Canada, and estimated an increase in $95 \%$ of fire weather severity during the summer months by 2070. Le Goff et al. (2009) also used regression analyses to model the recent climate-fire activity relationship, using FWI and GCM outputs to estimate climate change impacts on future fire risk in eastern Canada, and concluded that the fire risk in August would double (+110\%) for 2100, while in May it could slightly decrease $(-20 \%)$. More recently, Westerling et al. (2011) performed a comprehensive study on large wildfire occurrence and burned area in California combining hydroclimate and landsurface characteristics, using outputs from 3 GCM for 2 different population growth and development SRES (B1 and A2) scenarios, and concluded that (1) initial changes in burned area will be modest, (2) mean burned area will increase in the $30 \mathrm{yr}$ periods centred in 2050 and 2085 by $7-41$ and $12-74 \%$, respectively, and (3) will exceed $400 \%$ in much of the forested areas of Northern California in every SRES A2 scenario by 2085.

In summary, both principal objectives of this work were achieved. (1) A simple (linear) and parsimonious BAM (with just 2 predictors that are different temporal summaries of the same variable, DSR) was developed to simulate the decimal logarithm of monthly burnt areas in the fire season (July and August). This model is based on the results of the composite analysis to assess the influence of weather on the fire regime, and is able to explain almost $2 / 3$ of the total observed variance. (2) An assessment of the potential impacts of climate change on the wildfire regime in mainland Portugal was performed by feeding the BAM with GCM outputs from SRES B1 scenario. Bias of the GCM and BAM were corrected $a$ posteriori by transforming 20C3M scenario burnt area time series in order to have the same mean and standard deviation as the observed ones, and apply- ing the same transformation to GCM outputs for the B1 scenario. This transformation is consistent with the normal distribution shown by the decimal logarithm of the monthly burned area values for present and future climate conditions. The wide-ranging character of this procedure must also be emphasized, as it can be applied to outputs from any (global or regional) circulation model, under distinct conditions (e.g. different scenarios) and for varied purposes. Finally, despite the limitations, the developed approach consistently points towards (1) an increasing risk of fire under future climate conditions and to an increasing possibility of having much larger fire events; (2) increasing inter-annual variability of the fire regime, which together with the positive bias, will have dramatic consequences at the social, economic and environmental levels. These conclusions may be even more dramatic, as an increase of the fire season length is expected in boreal and temperate climates (Flannigan et al. 2009a, Wotton et al. 2010, Carvalho et al. 2011, Westerling et al. 2011, Kloster et al. 2012).

Acknowledgements. This work was supported by the EU 7th Framework Program (FUME) contract no. 243888 and by the Portuguese Science Foundation (FCT) through project FLAIR (PTDC/AAC-AMB/104702/2008). This work was also supported by European Union Funds (FEDER/COMPETE Operational Competitiveness Programme) and by national funds (FCT - Portuguese Foundation for Science and Technology) under the project FCOMP-01-0124-FEDER-022692. The authors are especially thankful to Dr. M. Abe from the Climate Risk Assessment Section, Center for Global Environmental Research, National Institute for Environmental Studies (CGER, NIES), for providing the MIROC data, and to C. Pinto Teixeira for the spelling and grammar review of the manuscript.

\section{LITERATURE CITED}

Ahlfeld DP (2006) Comparison of climate model precipitation forecasts with North American observations. Proc XVI Int Conf Computational Methods Water Resour

Aldersley A, Murray SJ, Cornell SE (2011) Global and regional analysis of climate and human drivers of wildfire. Sci Total Environ 409:3472-3481

Berrisford P, Dee D, Poli P, Brugge R and others (2011) The ERA-Interim Archive, 2nd edn. ERA Rep Ser 1

Brown TJ, Hall BL, Mohrle CR, Reinbold HJ (2002) Coarse assessment of Federal Wildland Fire Occurrence data. CEFA Rep 02-04, available at http://cefa.dri.edu/Publications/fireoccurrencereport.pdf

Calado TJ, DaCamara CC (2008) Dating fire events on end of season maps of burnt scars. In: Soares A, Pereira MJ, Dimitrakopoulos R (eds) geoENV VI: geostatistics for environmental applications. Springer, Berlin, p 323-333

Carvalho A, Flannigan M, Logan K, Miranda A, Borrego C (2008) Fire activity in Portugal and its relationship to 
weather and the Canadian Fire Weather Index System. Int J Wildland Fire 17:328-338

> Carvalho A, Flannigan MD, Logan KA, Gowman LM, Miranda AI, Borrego C (2010) The impact of spatial resolution on area burned and fire occurrence projections in Portugal under climate change. Clim Change 98: 177-197

- Carvalho A, Monteiro A, Flannigan M, Solman S, Miranda AI, Borrego C (2011) Forest fires in a changing climate and their impacts on air quality. Atmos Environ 45: 5545-5553

> Cary GJ, Keane RK, Gardner RH, Lavorel S and others (2006) Comparison of the sensitivity of landscape-firesuccession models to variation in terrain, fuel pattern, climate and weather. Landscape Ecol 21:121-137

CFS (Canadian Forest Service) (2011) Canadian Wildland Fire Information System. http://cwfis.cfs.nrcan.gc. ca/en_CA/background/summary/fwi (accessed 25 November 2011)

> Costa L, Thonicke K, Poulter B, Badeck FW (2010) Sensitivity of Portuguese forest fires to climatic, human, and landscape variables: subnational differences between fire drivers in extreme fire years and decadal averages. Reg Environ Change 11:543-551

> Dee DP, Uppala SM, Simmons AJ, Berrisford B and others (2011) The ERA-Interim reanalysis: configuration and performance of the data assimilation system. Q J R Meteorol Soc 137:553-597

> Dimitrakopoulos A, Vlahou M, Anagnostopoulou CG, Mitsopoulos ID (2011) Impact of drought on wildland fires in Greece: implications of climatic change? Clim Change 109:331-347

> Dissing D, Verbyla DL (2003) Spatial patterns of lightning strikes in interior Alaska and their relations to elevation and vegetation. Can J Forest Res 33:770-782

Durão RM, Corte-Real J (2006) Alterações climáticas: futuro dos acontecimentos extremos e do risco de incêndio. In: Pereira JS, Pereira JMC, Rego JC, Silva JMN, Silva TP (eds) Incêndios florestais em Portugal. ISA PRESS, Lisboa

Efron B, Tibshirani R (1993) An introduction to the bootstrap. Chapman \& Hall/CRC, Boca Raton, FL

> Errasti I, Ezcurra A, Sáenz J, Ibarra-Berastegi G (2010) Validation of IPCC AR4 models over the Iberian Peninsula. Theor Appl Climatol 103:61-79

> Flannigan MD, Logan KA, Amiro BD, Skinner WR, Stocks BJ (2005) Future area burned in Canada. Clim Change 72:1-16

Flannigan MD, Krawchuk MA, de Groot WJ, Wotton BM, Gowman LM (2009a) Implications of changing climate for global wildland fire. Int J Wildland Fire 18:483-507

Flannigan MD, Stocks BJ, Turetsky MR, Wotton BM (2009b) Impacts of climate change on fire activity and fire management in the circumboreal forest. Glob Change Biol 15:549-560

Gillett NP, Weaver AJ, Zwiers FW, Flannigan MD (2004) Detecting the effect of climate change on Canadian forest fires. Geophys Res Lett 31:L18211, doi:10.1029/ 2004GL020876

Hasumi H, Emori S (2004) K-1 coupled model (MIROC) description. K-1. Tech Rep 1. Center for Climate System Research, University of Tokyo

IPCC (Intergovernmental Panel on Climate Change) (2007) Climate change 2007: the physical science basis. Summary for policy makers. Contributions of Working Group I to the Fourth Assessment Report of the Intergovernmental Panel on Climate Change. Cambridge University Press, Cambridge

Kloster S, Mahowald NM, Randerson JT, Lawrence PJ (2012) The impacts of climate, land use, and demography on fires during the 21st century simulated by CLM-CN. Biogeosciences 9:509-525

Krawchuk MA, Moritz MA, Parisien MA, Van Dorn J, Hayhoe K (2009) Global pyrogeography: the current and future distribution of wildfire. PLoS ONE 4:e5102, doi: 10.1371/journal.pone.0005102

> Le Goff H, Flannigan MD, Bergeron Y (2009) Potential changes in monthly fire risk in the eastern Canadian boreal forest under future climate change. Can J For Res 39:2369-2380

Le Page Y, Oom D, Silva JMN, Jönsson P, Pereira JMC (2010) Seasonality of vegetation fires as modified by human action: observing the deviation from eco-climatic fire regimes. Global Ecol Biogeogr 19(4):575-588

> Liu Y, Stanturf J, Goodrick S (2010) Trends in global wildfire potential in a changing climate. For Ecol Manag 259: 685-697

> Lucarini V, Calmanti S, Dell'Aquila A, Ruti PM, Speranza A (2006) Intercomparison of the northern hemisphere winter mid-latitude atmospheric variability of the IPCC. Clim Dyn 28:829-848

> Lynch AH, Beringer J, Kershaw P, Marshall A and others (2007) Using the paleorecord to evaluate climate and fire interactions in Australia. Annu Rev Earth Planet Sci 35: 215-239

- Marques S, Borges JG, Garcia-Gonzalo J, Moreira F and others (2011) Characterization of wildfires in Portugal. Eur J For Res 130:775-784

Maxino CC, McAvaney BJ, Pitman AJ, Perkins SE (2008) Ranking the AR4 climate models over the Murray Darling Basin using simulated maximum temperature, minimum temperature and precipitation. Int J Climatol 28: 1097-1112

Nakicenovic N, Alcamo J, Davis G, de Vries B and others (2000) Special Report on Emissions Scenarios. A Special Report of Working Group III of the Intergovernmental Panel on Climate Change. Cambridge University Press, Cambridge

Nieto S, Rodríguez-Puebla C (2006) Comparison of precipitation from observed data and general circulation models over the Iberian Peninsula. J Clim 19:4254-4275

Nitschke CR, Innes JL (2008) Climatic change and fire potential in South-Central British Columbia, Canada. Glob Change Biol 14:841-855

Palheiro PM, Fernandes P, Cruz MG (2006) A fire behaviour-based fire danger classification for maritime pine stands: comparison of two approaches. Forest Ecol Manag 234:S54

Pausas JG (2004) Changes in fire and climate in the eastern Iberian Peninsula (Mediterranean Basin). Clim Change 63:337-350

Pausas JG, Bradstock RA (2007) Fire persistence traits of plants along a productivity and disturbance gradient in Mediterranean shrublands of south-east Australia. Glob Ecol Biogeogr 16:330-340

Pereira JS, Correia AV, Correia AP, Pereira JMC and others (2002) Forests and biodiversity. In: Santos FD, Forbes K, Moita R (eds) Climate change in Portugal. Scenarios, impacts and adaptation measures. Gradiva, Lisboa, p 369-413 
Pereira MG, Trigo RM, DaCamara CC, Pereira JMC, Leite SM (2005) Synoptic patterns associated with large summer forest fires in Portugal. Agric For Meteorol 129: $11-25$

> Pereira MG, Malamud BD, Trigo RM, Alves PI (2011) The history and characteristics of the 1980-2005 Portuguese rural fire database. Nat Hazards Earth Syst Sci 11: 3343-3358

Scherrer SC (2010) Present-day interannual variability of surface climate in CMIP3 models and its relation to future warming. Int $\mathrm{J}$ Climatol 31:1518-1529, doi: 10.1002/joc. 2170

Solomon S, Qin D, Manning M, Alley RB and others (2007) Technical Summary. In: Solomon S, Qin D, Manning M, Chen $\mathrm{Z}$ and others (eds) Climate Change 2007: the physical science basis. Contribution of Working Group I to the Fourth Assessment Report of the Intergovernmental Panel on Climate Change. Cambridge University Press, Cambridge

Stephenson NL (1998) Actual evapotranspiration and deficit: biologically meaningful correlates of vegetation distribution across spatial scales. J Biogeogr 25:855-870

Tebaldi C, Hayhoe K, Arblaster J, Meehl GA (2006) Going to the extremes. An intercomparison of model-simulated historical and future changes in extreme events. Clim Change 79:185-211

Trigo RM, Pereira JMC, Pereira MG, Mota B, Calado TJ, DaCamara CC, Santo FE (2006) Atmospheric conditions associated with the exceptional fire season of 2003 in Portugal. Int J Climatol 26:1741-1757

van Wagner CE (1987) Development and structure of the Canadian Forest Fire Index System. For Tech Rep 35, Canadian Forestry Service, Ottawa

van Wagner CE, Picket TL (1985) Equations and FORTRAN

Editorial responsibility: Nils Chr. Stenseth, Oslo, Norway program for the Canadian Forest Fire Weather Index System. For Tech Rep 33, Canadian Forestry Service, Ottawa

> Viegas DX, Bovio G, Ferreira A, Nosenzo A, Sol B (1999) Comparative study of various methods of fire danger evaluation in Southern Europe. Int J Wildland Fire 9: 235-246

> Viegas DX, Piñol J, Viegas MT, Ogaya R (2001) Estimating live fine fuels moisture content using meteorologicallybased indices. Int J Wildland Fire 10:223-240

Westerling AL, Brown TJ, Gershunov A, Cayan DR, Dettinger MD (2003) Climate and wildfire in the western United States. Bull Am Meteorol Soc 84:595-604

Westerling AL, Hidalgo HG, Cayan DR, Swetnam T (2006) Warming and earlier spring increases western US forest wildfire activity. Science 313:940-943

- Westerling AL, Bryant BP, Preisler HK, Holmes TP, Hidalgo HG, Das T, Shrestha SR (2011) Climate change and growth scenarios for California. Clim Change 109(suppl 1):S445-S463

Wilks DS (1995) Statistical methods in the atmospheric sciences: an introduction. Academic Press, San Diego, CA

- Wotton BM (2008) Interpreting and using outputs from the Canadian Forest Fire Danger Rating System in research applications. Environ Ecol Stat 16:107-131, doi:10.1007/ s10651-007-0084-2

Wotton BM, Flannigan MD (1993) Length of the fire season in a changing climate. For Chron 69:187-192

Wotton BM, Martell DM, Logan KA (2003) Climate change and people-caused forest fire occurrence in Ontario. Clim Change 60:275-295

Wotton BM, Nock CA, Flannigan MD (2010) Forest fire occurrence and climate change in Canada. Int J Wildland Fire 19:253-271

Submitted: September 4, 2012; Accepted: June 24, 2013 Proofs received from author(s): September 30, 2013 